J.Lake Sci.(湖泊科学), 2016, 28( 1): 40-49

DOI 10. 18307/2016. 0105

(C) 2016 by Journal of Lake Sciences

\title{
巢湖表层沉积物中生物易降解物质成分特征与分布规律
}

\author{
何延召 ${ }^{1,2}$, 柯 凡 ${ }^{1 * *}$, 冯慕华 ${ }^{1}$, 李文朝 ${ }^{1}$, 陈向超 ${ }^{1,2}$, 周 峰 $^{3}$ \\ (1: 中国科学院南京地理与湖泊研究所湖泊与环境国家重点实验室, 南京 210008) \\ (2: 中国科学院大学, 北京 100049) \\ (3:西北大学城市与环境学院,西安 710127)
}

\begin{abstract}
摘 要: 富营养化湖泊的藻类残体大量沉降到湖底, 其中易降解成分的降解和转化快速消耗底层水体中的溶解氧, 极易 造成水土界面缺氧, 影响湖泊生态系统的健康. 于 2014 年对巢湖 12 个样点的表层沉积物进行周年跟踪研究, 分析样品中 有机质来源、总有机碳 (TOC) 、蛋白质、总糖、总脂以及生物聚合物碳 (BPC) 等成分含量, 揭示易降解有机质的成分特征 及在巢湖的分布规律. 研究表明: 巢湖表层沉积物 TOC 含量较高, 全湖样点平均含量达到 $1.24 \%$. BPC 含量占 TOC 含量的 $30.99 \% \sim 60.48 \%$, 有机质中易降解成分含量较高, 并且在冬季和夏季时在巢湖西北部湖区有明显累积; 有机质及其中的 生物易降解部分均主要集中在粒径 $4 \sim 8 \mu \mathrm{m}$ 的表层沉积物上,在应用工程技术手段处理、降解表层沉积物中的过量有机 质时,更应该关注粒径为 $4 \sim 8 \mu \mathrm{m}$ 的沉积物颗粒.
\end{abstract}

关键词: 巢湖; 表层沉积物; 有机质;生物易降解成分

\section{Characteristics and distribution of biodegradable compounds of surface sediments in Lake Chaohu}

\author{
HE Yanzhao ${ }^{1,2}$, KE Fan $^{1 * *}$, FENG Muhua ${ }^{1}$, LI Wenchao ${ }^{1}$, CHEN Xiangchao ${ }^{1,2}$ \& ZHOU Feng ${ }^{3}$ \\ (1: State Key Laboratory of Lake Science and Environment, Nanjing Institute of Geography and Limnology, Chinese Academy \\ of Sciences, Nanjing 210008, P.R. China) \\ (2: University of Chinese Academy of Sciences, Beijing 100049, P.R.China) \\ (3: College of Urban and Environmental Science, Northwest University, Xi'an 710127, P.R. China)
}

Abstract: In eutrophic lakes large amount of algae detritus fall down to the lake bottoms every year. Dissolved oxygen in water would be consumed rapidly by labile compositions during degradation and transformation of the organic detritus, which can easily cause water hypoxia, affecting the health of lake ecosystem. Throughout the 4 seasons of 2014, 12 sampling sites for collected from surface sediments in Lake Chaohu were chosen to study the biodegradable organic components. In order to study characteristics of the labile components within the detritus and the distribution in the lake, source of organic matter, TOC, PRT, CHO, LPD and BPC contents in the samples were analyzed. Results have shown that the content of organic matter of surface sediments in Lake Chaohu is high, the average content reached 1.24\%. BPC content accounts for 30.99\% to $60.48 \%$ of TOC. The biodegradable organic components were relatively high, which accumulated obviously in northwestern Chaohu in winter and summer. The organic matter and biodegradable parts of surface sediments mainly adsorbed on the particle size of $4-8 \mu \mathrm{m}$, so that the particles ranged from 4$8 \mu \mathrm{m}$ should be concerned when we use engineering measures to deal with excess organic matter in surface sediments.

Keywords: Lake Chaohu; surface sediments; organic matter; biodegradable compounds

巢湖位于安徽省中部 $\left(31^{\circ} 25^{\prime} 28^{\prime \prime} \sim 31^{\circ} 43^{\prime} 28^{\prime \prime} \mathrm{N}, 117^{\circ} 16^{\prime} 54^{\prime \prime} \sim 117^{\circ} 51^{\prime} 46^{\prime \prime} \mathrm{E}\right)$, 属河成型浅水湖, 是我国五大

* 国家自然科学基金项目 (41171366,41471075)、国家水体污染控制与治理科技重大专项(2012ZX07103-005-01) 和 中国科学院南京地理与湖泊研究所 “一三五” 战略发展规划项目联合资助.2015-01-19 收稿; 2015-03-27 收修 改稿.何延召(1988 ), 男, 硕士研究生; E-mail:wyyzhhe@163.com.

** 通信作者; E-mail: fke@ niglas.ac.cn. 
淡水湖之一. 湖泊长度 $61.7 \mathrm{~km}$, 平均宽度 $12.5 \mathrm{~km}$, 湖面面积 $756 \mathrm{~km}^{2}$, 平均水深 $3.06 \mathrm{~m}$, 蓄水量 $20.7 \times 10^{8} \mathrm{~m}^{3}$. 湖区属北亚热带季风气候,年均气温 $16.1^{\circ} \mathrm{C}$. 巢湖人湖水系主要有: 新河、塘西河、十五里河、店埠河、柘臬河 等, 由裕溪河连接巢湖汇人长江. 巢湖闸等水利工程的建设严重妨碍了巢湖与长江水体间的自然交换能力, 使得巢湖自然换水周期过长, 进而改变了巢湖的生态学特征. 自 1970s 以来, 随着工农业的发展, 大量的氮、 磷输人巢湖, 导致湖泊富营养化 ${ }^{[1]}$, 巢湖西半湖较东半湖污染更为严重 ${ }^{[2-3]}$. 由于水质的恶化, 巢湖蓝藻水华 暴发频次总体呈现出上升趋势, 发生区域呈扩大趋势, 发生时间呈延长趋势 ${ }^{[4]}$, 蓝藻密度不断升高, 死亡的 蓝藻沉积到湖底,形成一层高含量有机质层.

湖底表层沉积物中积累的大量有机质在降解和转化过程中将对湖泊水质与环境产生负面影响.已有研 究指出某些有机成分在水生生态系统中降解和转化速度比较快 ${ }^{[5-7]}$, 在温度适宜的季节, 这些有机成分通过 自然分解, 不仅会向水体释放营养物质,加剧水体富营养化, 同时有机物的氧化会迅速消耗水体中的溶解 氧 ${ }^{[8]}$, 引起水体缺氧, 导致湖泊水体中 “湖泛” 的发生 ${ }^{[9-12]}$. 湖底沉积物中的有机质由易降解和难降解成分组 成, 在早期成岩过程中, 沉积物中有机质含量总体相对稳定 ${ }^{[13]}$, 经过一系列复杂的过程 (包括降解、异养利 用、转移、累积和输出), 它们的相对重要性随之发生变化 ${ }^{[14]}$. 表层沉积物中的易降解成分可以影响底层动物 群落动力学和新陈代谢 ${ }^{[5-18]}$, 有机质中易降解部分含量也可以用来评估生态系统的营养状态 ${ }^{[18-19]}$. 然而目 前关于湖泊沉积物的研究主要集中在有机质含量与来源、营养盐含量及释放特征、粒度分布、重金属含量、 持久性有机污染物含量分布等方面 ${ }^{[20-25]}$, 而针对沉积物有机质中容易降解的成分特征和分布的研究较少.

易降解有机质成分复杂, 需要应用合适的方法和指标进行研究. 易降解有机成分从生物化学的角度主要 分为蛋白质 (PRT)、总糖 ( CHO) 、总脂 (LPD) 3 类, 其降解难易程度为: 蛋白质>总糖>总脂 ${ }^{[26]}$. 对藻细胞组分 的研究发现, 藻细胞主要由蛋白质、糖类和脂类物质组成, 他们的相对含量因藻种类的不同而有所差异 ${ }^{[27]}$. 通常蓝藻中蛋白质含量较高 $(41 \% \sim 69 \%)$, 而硅藻中脂类含量较高 $(5 \% \sim 43 \%)^{[28-30]}$. 然而这些生物化学成分 并不完全由碳组成, 并不能完全代表生物易降解成分的含量, 而要从生物可利用碳来分析其易降解成分含 量.Lopez-Fernandez 等 ${ }^{[31]}$ 研究了地中海西北部布拉内斯峡谷沉降颗粒有机质中生物可利用化合物的含量变 化, 使用生物聚合物碳 (BPC) 指标来对易降解成分进行综合描述, 取得了较好的结果. 由于 BPC 指标能够更 好地代表更容易被降解利用的有机成分的总量, 并且对易降解的有机质成分在时间上的变化有较高的灵敏 度, 因此非常适宜用来表征有机质中的易降解成分含量 ${ }^{[13,18,32-35]}$. 由于生物易降解物质是细菌和底栖小型生 物的主要物质能量来源, 因此对生物易降解成分分布规律的监控具有重要意义.

在前人研究的引导下, 本文分不同季度采集巢湖表层沉积物进行为期 1 周年的调查, 主要目的是解决 以下几个问题: (1) 目前巢湖表层沉积物中有机质含量分布; (2) 沉积物有机质中易降解成分占到多大的 比例; ( 3) 易降解有机质在时间、空间以及沉积物颗粒中的分布存在什么样的规律.

\section{1 材料和方法}

\section{1 研究区域及样品的采集}

在巢湖总共设置 12 个采样点 (图 1), 其中西湖区 5 个( C-1 C-5)、中湖区 2 个(C-6、C-7)、东湖区 5 个 (C-8 C-12). 分别于 2014 年 1 月 (冬季)、4 月 (春季)、7 月(夏季) 及 10 月 (秋季) 用内径为 $110 \mathrm{~mm}$ 的柱状 采泥器采集各样点的沉积物柱状样品, 取表层 $1 \mathrm{~cm}$ 样品放人密封袋中带回实验室分析. 在干燥处理前置于 $-20^{\circ} \mathrm{C}$ 下冷冻 ${ }^{[6-38]}$. 由于湖底沉积物采样的特殊性以及天气原因, 用柱状采泥器并未采集到冬季 C-7 和 $\mathrm{C}-10$ 样点、春季 C-11 样点及秋季 C-9 样点的沉积物样品.

\section{2 样品预处理}

冷冻的沉积物样品用 Labconco 冷冻干燥机 (型号: 7948030) 冻干, 用玛瑙研钭研磨, 过 200 目尼龙篮后, 装人样品袋密封,避光、干燥保存.

\section{3 样品分析}

1.3.1 粒度分析 将新鲜样品混合均匀, 用药匙从样品袋中取 $0.2 \mathrm{~g}$ 左右置于 $100 \mathrm{ml}$ 烧杯中, 加 $10 \%$ 双氧水 溶液 $10 \mathrm{ml}$, 放到电热板上加热至反应完成; 然后加人 $10 \mathrm{ml} 10 \%$ 的盐酸溶液, 再注满水静置过夜; 待样品浸 泡好后, 小心将上清液倒出, 剩余约 $10 \mathrm{ml}$ 即可; 再在样品中加人 $10 \mathrm{ml}$ 六偏磷酸钠, 于超声波振荡仪中振荡 


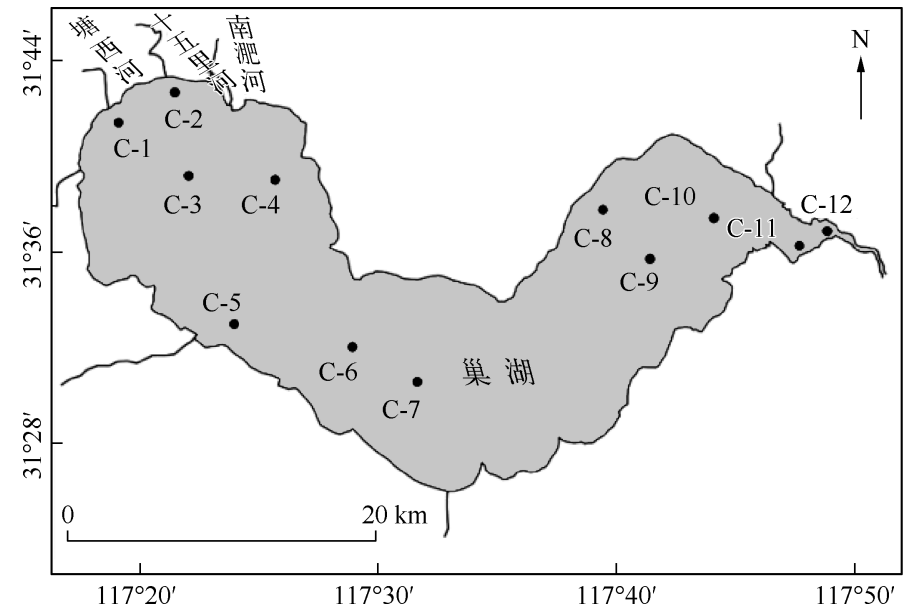

图 1 巢湖采样点位分布 $(\mathrm{C}-1$ : 塘西河人湖区; C-2: 十五里河人湖区; C-3:西湖心; $\mathrm{C}-4$ : 湖滨; C-5 : 新河人湖区 ; C-6: 中庙; C-7 : 中湖心 ; C-8 : 烔炀河人湖区 ; C-9 : 东湖心 ; C-10 : 中垾; $\mathrm{C}-11$ :巢湖船厂; C-12:西坝口)

Fig.1 Distribution of sampling sites in Lake Chaohu

$15 \mathrm{~min}$; 振荡后的样品采用英国 Malvern 公司生产的 Mastersizer 2000 型激光粒度仪测定, 测量范围为 $0.02 \sim$ $2000 \mu \mathrm{m}^{[39]}$.粒径分布参考李强等 ${ }^{[20]}$ 的划分方法以百分含量表示.

1.3.2 总有机碳 (TOC) 含量分析 将适量的干燥样品放人事先称过重的离心管中, 并进行称重, 然后加 人 $\geqslant 2 \mathrm{ml}$ 的 $\operatorname{HCl}(1: 3 \mathrm{v} / \mathrm{v})$, 震荡使其充分反应, 静置 $18 \mathrm{~h}^{[40]}$, 用蒸馏水洗至中性后用冻干机冻干, 用 $\mathrm{CHN}$ (EURO EA 3000) 元素分析仪测定 TOC 和总氮 (TN) 含量( 以\% 表示), 并计算 TOC 与 TN 的比值 $(\mathrm{C} / \mathrm{N}$ ).

1.3.3 易降解成分的分析 称取一定量的沉积物样品用改进的 Lowry 法测定蛋白质含量, 牛血清蛋白做标 线 ${ }^{[41-43]}$; 用苯酚一硫酸法测定总糖含量, 以葡萄糖做标线 ${ }^{[44]}$; 用甲醇一氯仿法测定总脂含量, 以甘油三酯做标 线 ${ }^{[45-47]}$.每个样品做 3 次重复, 并计算平均值及标准偏差.

\section{4 计算方法}

蛋白质碳、总糖碳、总脂碳的加和称为 BPC, 用来估算有机质中易降解部分的含量 ${ }^{[13]}$, 计算公式 ${ }^{[48]}$ 为:

$$
\mathrm{BPC}=0.40 \mathrm{CHO}+0.49 \mathrm{PRT}+0.75 \mathrm{LPD}
$$

\section{5 数据处理}

采用 Origin 9.0 软件对数据作图, 其中误差线为标准偏差 (SE) ; 采用 SPSS 18.0 软件中的 Pearson 法进行 不同参数之间的相关性分析; 用 Sufer 9.0 克里金插值法绘制等值线图.

\section{2 结果与讨论}

\section{1 有机质的来源}

通过沉积物有机质的 $\mathrm{C} / \mathrm{N}$ 比值可以大体判断有机质的来源是湖泊自生还是外源输人. 由于藻类有机质 中富含大量的蛋白质, 纤维素的含量较低; 而陆生高等植物富含纤维素, 蛋白质含量低. 可以根据沉积物中有 机质的 $\mathrm{C} / \mathrm{N}$ 来判定其有机质来源: 来自脉管类陆生高等植物有机质的 $\mathrm{C} / \mathrm{N}$ 约为 20 , 甚至更高, 而内源藻类 有机质的 $\mathrm{C} / \mathrm{N}$ 通常在 $4 \sim 10$ 之间, 沉积物中有机质的 $\mathrm{C} / \mathrm{N}>10$, 常常被认为是受到两种物源的影响 ${ }^{[49]}$. 巢湖 各样点表层沉积物的 $\mathrm{C} / \mathrm{N}$ 比值相差不大, 在 7.28 9.95 之间, 平均为 8.14(表 1). 除东湖区的 C-11、C-12样点 $\mathrm{C} / \mathrm{N}$ 比值略有变化外, 其他样点 4 个季节 $\mathrm{C} / \mathrm{N}$ 比值没有明显变化. 巢湖表层沉积物 $\mathrm{C} / \mathrm{N}$ 均小于 10 , 表明沉 积物中有机质主要受到水生物源的影响, 以自生有机物源为主. 近几十年来, 巢湖由于受到外源污染的影响, 大量的营养物质流人水体, 但是本研究各河流人湖区样点距河口大于 $2 \mathrm{~km}$, 所研究样点主要受内源的影响, 且已有大量研究表明巢湖西北部湖区受蓝藻污染严重 ${ }^{[2-3,50]}$, 死亡蓝藻的沉降是导致该区域 $\mathrm{C} / \mathrm{N}$ 低的主要原 
因.1960s 巢湖闸建成后, 巢湖成了半封闭性水域, 水流减缓, 同时由于外源营养物质的过度排放,刺激湖内 藻类繁殖; 风向和较高的营养水平的共同作用导致蓝藻频发, 死亡藻类的长期沉降累积使其成为巢湖沉积 物中有机质的主要来源 ${ }^{[1]}$.

表 1 巢湖各样点表层沉积物 $\mathrm{C} / \mathrm{N}$ 和 BPC/TOC 的变化

Tab.1 The variation of $\mathrm{C} / \mathrm{N}$ and BPC/TOC from surface sediments of each sampling site in Lake Chaohu

\begin{tabular}{|c|c|c|c|c|c|c|c|c|}
\hline \multirow{2}{*}{ 样点 } & \multicolumn{4}{|c|}{$\mathrm{C} / \mathrm{N}$} & \multicolumn{4}{|c|}{ BPC/TOC/\% } \\
\hline & 冬季 & 春季 & 夏季 & 秋季 & 冬季 & 春季 & 夏季 & 秋季 \\
\hline C-1 & 8.66 & 7.66 & 8.32 & 7.77 & 40.37 & 38.22 & 33.11 & 37.85 \\
\hline $\mathrm{C}-2$ & 8.74 & 8.67 & 9.26 & 9.18 & 40.63 & 34.33 & 41.08 & 30.99 \\
\hline C-3 & 8.01 & 7.58 & 7.81 & 8.12 & 51.06 & 36.42 & 40.47 & 34.69 \\
\hline C-4 & 7.97 & 7.75 & 8.31 & 8.06 & 51.16 & 52.03 & 38.77 & 39.77 \\
\hline C-5 & 8.60 & 7.70 & 7.71 & 8.06 & 52.99 & 60.48 & 42.28 & 54.02 \\
\hline C-6 & 8.30 & 7.63 & 7.54 & 8.14 & 51.21 & 56.39 & 41.43 & 47.35 \\
\hline C-7 & - & 7.82 & 7.65 & 7.61 & - & 46.16 & 45.97 & 43.17 \\
\hline C-8 & 8.61 & 7.40 & 7.33 & 7.91 & 51.25 & 46.59 & 39.77 & 38.81 \\
\hline C-9 & 8.07 & 7.28 & 7.79 & - & 51.08 & 40.57 & 38.74 & - \\
\hline C-10 & - & 7.70 & 7.75 & 7.79 & - & 40.46 & 35.95 & 39.60 \\
\hline C-11 & 8.45 & - & 9.13 & 9.95 & 45.97 & - & 34.45 & 41.33 \\
\hline C-12 & 7.97 & 8.39 & 8.38 & 9.56 & 45.42 & 43.05 & 41.14 & 43.02 \\
\hline
\end{tabular}

\section{2 沉积物有机成分的含量}

2014 年巢湖表层沉积物中 TOC 含量变化不大, 在 $0.42 \% \sim 1.81 \%$ 之间, 平均为 $1.24 \%$ ( 图 2a), 比 2011 年 巢湖表层沉积物 TOC 含量 (平均为 $5.987 \mathrm{~g} / \mathrm{kg}$ ) 高 ${ }^{[20]}$; 远高于太湖沉积物 TOC 高值区 $(\geqslant 2.30 \mathrm{~g} / \mathrm{kg}$ ) 竺山湾、 西部沿岸区、梅梁湾、贡湖地区 (平均值为 $1.59 \mathrm{~g} / \mathrm{kg}$ ) ${ }^{[52]}$, 根据天然水体“Dead Zones”形成 4 阶段理论一一藻 类有机质大量累积、偶尔出现缺氧、经常性出现缺氧、厌氧并释放 $\mathrm{H}_{2} \mathrm{~S}^{[53]}$, 巢湖沉积物中 TOC 含量已经满足 发生黑水团的首要条件.TOC 含量总体上呈现西湖区高、中湖区最低的趋势; 其中最大值出现在西湖区的 C-1、 C-2 样点, 最小值出现在东湖区的 C-11 样点; 西湖区的 C-5 C-1 样点呈现出逐渐增大的趋势. 中、西湖区各 样点 4 个季度 TOC 含量变化不大, 东湖区 C-10 C-12 样点 TOC 含量在不同季节略有差异. 虽然外源营养的 输人以及蓝藻水华暴发造成巢湖污染比较严重, 但是由于巢湖是浅水湖泊, 沉积物一水界面生物化学作用非 常活跃, 部分有机质在沉降过程或沉积后被快速降解, 导致巢湖沉积物中有机质含量明显低于水质较好的 深水湖泊程海 $(2.76 \% \text { )、青海湖 (2.978\%) })^{[54]}$ 和抚仙湖 (南部: $9.232 \%$, 中部: 6.614\%, 北部: $\left.2.76 \%\right)^{[55]}$. 巢湖 西湖区水质处于重富营养化状态 (2013 年出现了叶绿素 a 浓度为 $1229.834 \mu \mathrm{g} / \mathrm{L}$ 的峰值 ${ }^{[50]}$ ), 蓝藻暴发频 繁, 大量藻类死亡后腐烂沉积, 造成西湖区沉积物 TOC 含量相对较高. 东湖区的 TOC 含量偏高主要与这一区 域也有蓝藻水华的暴发有关 ${ }^{[4]}$ ( 2013 年东北部的叶绿素 a 浓度显著增加, 大范围的区域均超出了 $163.12 \mu \mathrm{g} / \mathrm{L}$, 并且在最东部出现了最高峰值 ${ }^{[50]}$ ) ; 同时也有可能受到巢湖闸外泄排水的影响, 有大量有机质 随水流流向该区域.

巢湖表层有机物中 PRT 含量在 $0.63 \sim 5.50 \mathrm{mg} / \mathrm{g}$ 之间, 平均值为 $3.69 \mathrm{mg} / \mathrm{g}$ ( 图 2b). 总体来看, 蛋白质含 量和 TOC 含量的分布变化趋势相近, 总体上呈现西湖区最高、中湖区最低的分布趋势, 其中最大值出现在西 湖区的 C-1、C-2 样点, 中湖区的 C-6、C-7 样点较低, 最小值出现在东湖区的 C-11 样点, 西湖区 C-4 C-1 样点 蛋白质含量有逐渐增加的趋势. 巢湖西湖区 (尤其是西北湖区) 是重污染湖区 ${ }^{[50]}$, 大量死亡藻类的沉降是导 致该区域蛋白质含量较高的主要原因; 从冬季到秋季, 除东湖区的 C-11、C-12 样点外, 各样点含量略有增加, 但是变化趋势不如 $\mathrm{CHO}$ 含量 (图 2c) 变化明显. 主要有两方面原因: 首先, 虽然巢湖表层沉积物有机质以蓝 藻及其死亡残体为主, 但是, 由于大量死亡藻类在沉降到湖底前, 蛋白质中最易降解的那部分基本已经降解 完全; 另外, 沉降到底部沉积物中的蛋白质由于蛋白酶的抑制作用, 使蛋白质更倾向于和难降解的化合物 结合 ${ }^{[56-57]}$. 

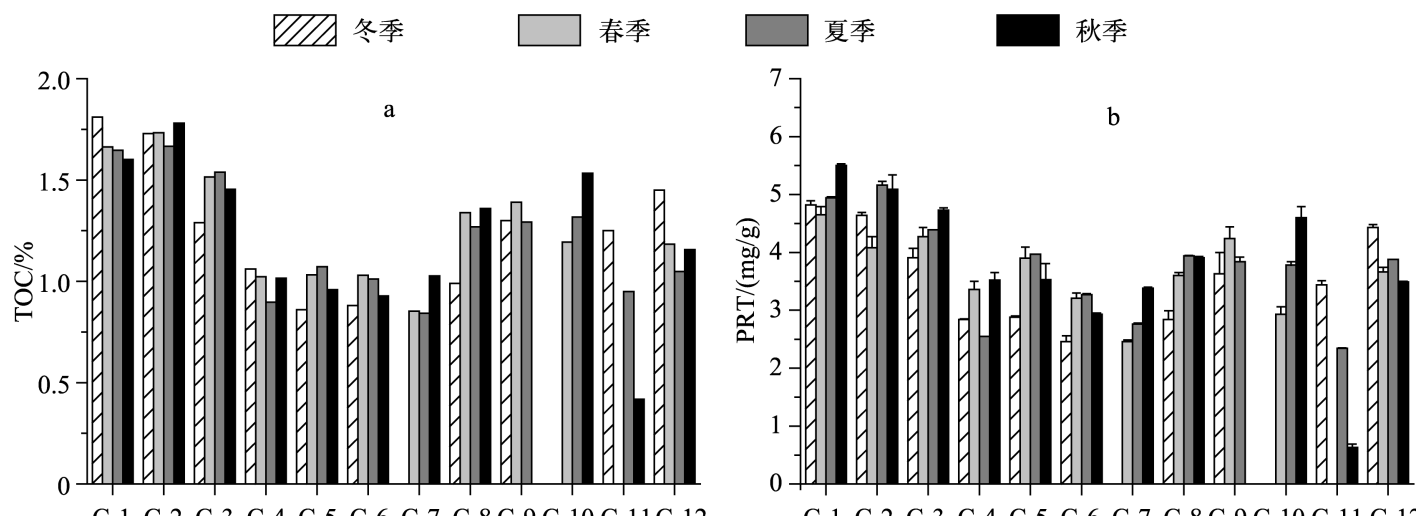

C-1 C-2 C-3 C-4 C-5 C-6 C-7 C-8 C-9 C-10 C-11 C-12
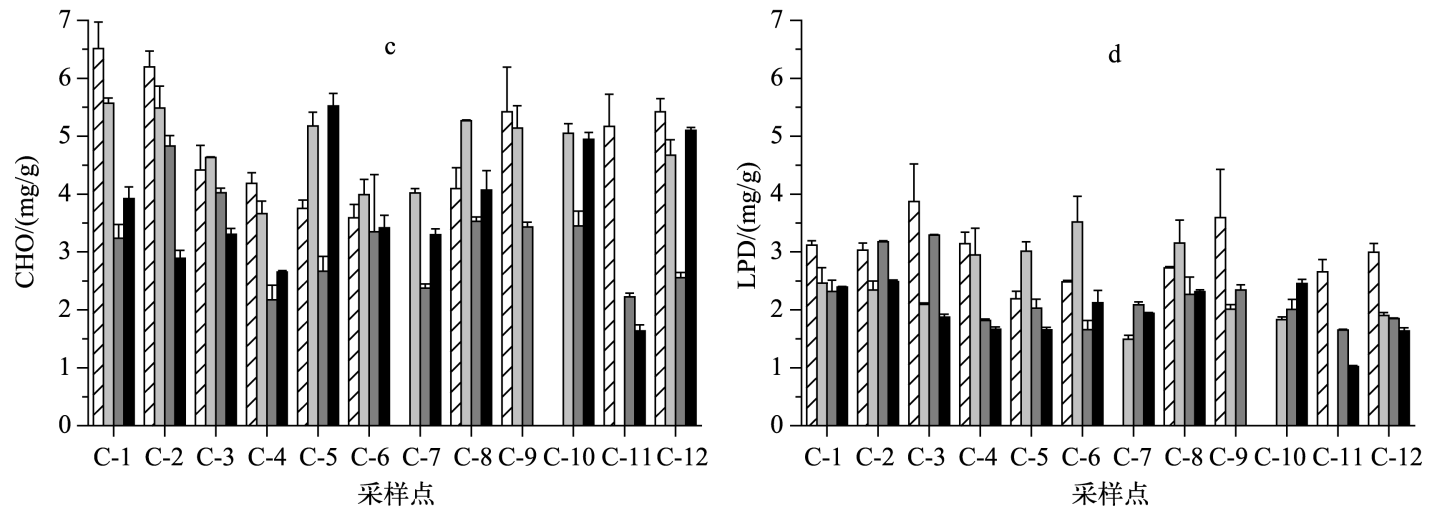

图 2 巢湖各样点表层沉积物中各成分含量

Fig.2 The contents of each composition from surface sediments of each sampling site in Lake Chaohu

巢湖表层沉积物中 CHO 含量在 $1.63 \sim 6.52 \mathrm{mg} / \mathrm{g}$ 之间, 平均为 $4.09 \mathrm{mg} / \mathrm{g}$ (图 2c $)$; 其中, 冬、春、夏季最大 值均出现在西湖区的 C-1、C-2 样点; 而秋季以 C-5 样点含量最高, 该样点位于新河人湖区, 新河蓝藻水华比 较严重,笔者所在研究团队所研制的“大型仿生式蓝藻清除设备”曾于 2013 年 9 月份在该河流进行过蓝藻 清除作业, 因此秋季该样点含量最高, 可能是由于新河大量死亡蓝藻输人所导致; 中湖区的 C-6、C-7 样点含 量最低, 主要是中部敞水区由于风浪的作用, 蓝藻不易在该区域堆积, 从而沉降到湖底的有机成分含量相应 较低. 从冬季到夏季, 各样点 $\mathrm{CHO}$ 含量有降低趋势, 以西湖区最为明显, 和巢湖沉积物中藻类生物量的变化 趋势一致 ${ }^{[58]}$; 到了秋季, $\mathrm{CHO}$ 含量略有增加. 由于蛋白质比糖更容易被底栖细菌所利用, 沉积物中 CHO 含量 较高和藻类有机碎屑的蓄积有关 ${ }^{[26]}$. 初步认为造成这种现象主要有 3 方面原因: 首先, 针对巢湖这样的浅水 富营养化湖泊,根据孔繁翔等 ${ }^{[59]}$ 对蓝藻水华形成 4 阶段机理 (休眠、复苏、生物量增加、上浮和积聚形成水 华) 的研究, 冬季越冬蓝藻沉降到湖底, 在水底黑暗条件下蓝藻生存环境薄弱, 但是由于大量沉积, 导致湖底 $\mathrm{CHO}$ 的蓄积; 到了春季, 湖底蓝藻开始复苏, 需要消耗一定的能量, 增加了对糖的消耗 ${ }^{[60]}$; 夏季温度更适合 湖底蓝藻的复苏及上升形成水华消耗大量的能量, $\mathrm{CHO}$ 的消耗进一步增加. 这是导致春、夏季 $\mathrm{CHO}$ 含量降 低的主要原因; 其次, 冬季 $\mathrm{CHO}$ 含量较高和蓝藻水华过后碎屑的沉降 ${ }^{[61]}$ 及湖底碎屑物质的后续降解有关; 最后, 冬季湖底温度较低, 用于降解湖底有机质的底栖生物量较少, 导致 CHO 的蓄积. 随着温度的回升, 底栖 生物活动增强, 加快了 $\mathrm{CHO}$ 的降解. 到了春、夏季, 湖底水温达到底栖生物的最佳温度, 底栖生物的活性此时 达到最强, 导致 CHO 含量的进一步降低.

已有研究表明沉积物中 LPD 主要来自硅藻和浮游动物排泄物 ${ }^{[62]}$. 巢湖表层沉积物中 LPD 含量为 $1.02 \sim$ $3.87 \mathrm{mg} / \mathrm{g}$, 平均值为 $2.38 \mathrm{mg} / \mathrm{g}$ (图 2d) ; 其中, 最大值出现在冬季的 C-3 样点, 最小值出现在秋季的 C-11 样 点; 各样点含量有所差异, 以西湖区的 C-1、C-2、C-3 样点相对较高. 各样点 LPD 含量低于 PRT 及 CHO 含量, 
主要是因为微囊藻和鱼腥藻是巢湖浮游植物优势种, 而硅藻并不是其优势种 ${ }^{[63]}$, 导致 LPD 总体含量较低. 冬 季 LPD 含量较高可能与硅藻残体和浮游动物排泄物沉降以及微生物活性的减弱有关 ${ }^{[61]}$.

\section{$2.3 \mathrm{BPC}$ 的分布特征}

BPC 含量代表容易被生物降解利用的有机成分的总量. 本研究的结果显示, 巢湖表层沉积物中 BPC 含 量占 TOC 含量的 30.99\% 60.48\% (表 1), 平均值为 $43.17 \%$, 所占比例相对较高.一方面, 虽然各样点 TOC 含 量年变化总体相对稳定 (图 2a, C-10 C-12 样点除外), 但是 BPC 含量和组成比例变化较大, BPC 的变化更 能反映湖底表层沉积物生产力的变化. 因此, 本研究用 BPC 来反映巢湖生物易降解成分不仅可行, 而且将其 用于描述有机碎屑沉降后的早期降解过程会具有较高的灵敏度. 另一方面, 尽管只有一部分 BPC 能够被快 速降解消耗 ${ }^{[19,64-65]}$, 但是已经有很多研究表明沉积物中底栖动物量与 BPC 含量及组成密切相关 ${ }^{[66-68]}$, 因此, 监控沉积物中的 BPC 含量及其在重污染湖泊中的分布有助于提前预知水体缺氧或者戻氧事件 ${ }^{[57]}$.

巢湖 2014 年冬、春、夏、秋 4 个季节表层沉积物中的 BPC 含量分布如图 3 所示, 其含量在 1.72 $7.31 \mathrm{mg} / \mathrm{g}$ 之间, 平均为 $5.23 \mathrm{mg} / \mathrm{g}$. BPC 含量的分布变化趋势和 CHO 含量相似: 空间总体呈现西湖区含量 高、中湖区含量低的分布趋势, 与巢湖蓝藻水华分布特征基本相符 ${ }^{[4]}$; 其中, 西北部湖区含量最高, 主要是由 于该区域是蓝藻重灾害湖区, 蓝藻暴发频繁, 死亡的蓝藻残体大量沉降所导致的; 春季西南湖区的新河人湖 区 BPC 含量较高可能是由河道带人的大量蓝藻造成的. 季节上总体呈现出冬春季含量高、夏季含量低的趋 势. $\mathrm{BPC}$ 含量的变化主要是由 $\mathrm{CHO}$ 含量的变化导致的, 初步认为蓝藻越冬沉降、复苏、夏季蓝藻水华过后蓝 藻碎屑的沉降以及因温度而导致的微生物量和活性的强弱是导致 BPC 含量呈现出图 3 所示分布趋势的几 个原因.

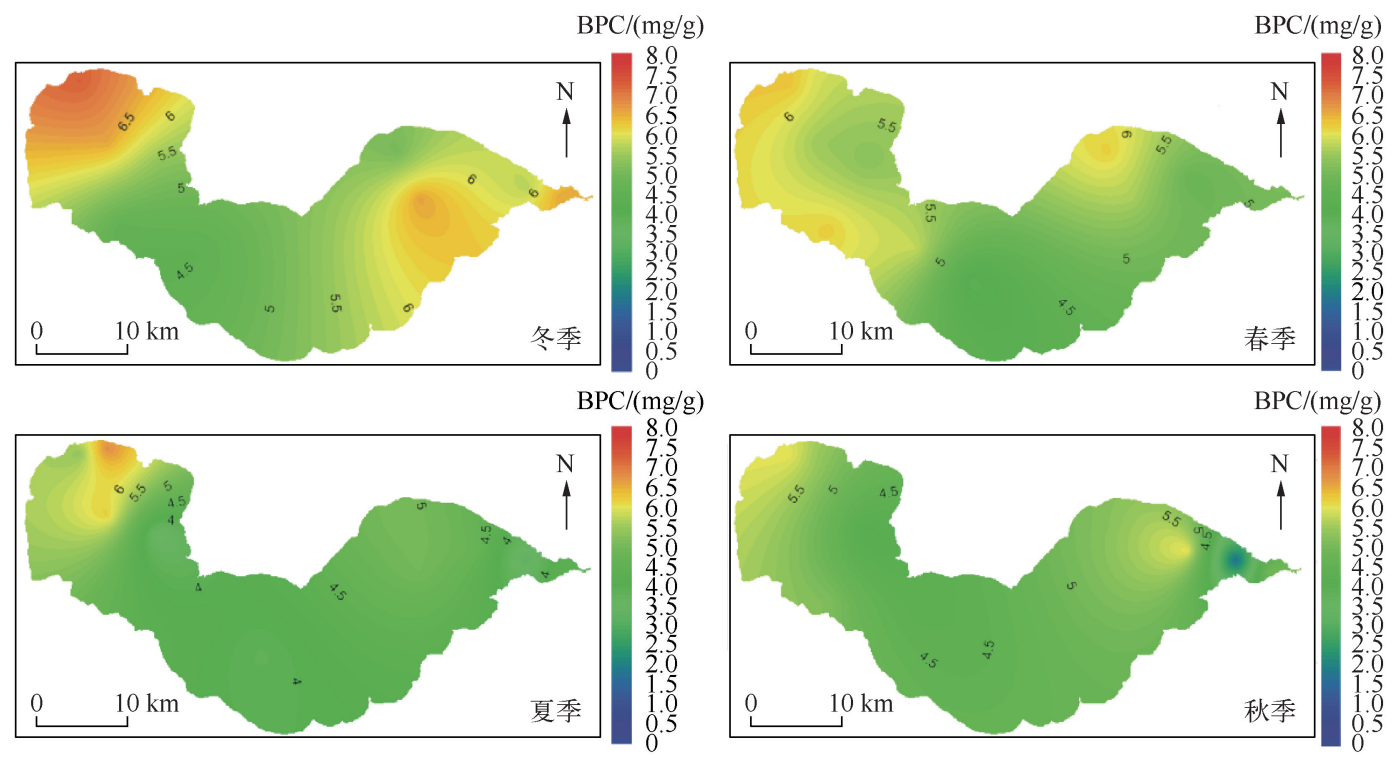

图 3 巢湖表层沉积物中 BPC 含量的分布变化

Fig. 3 The distribution and variation of BPC content of surface sediments in Lake Chaohu

\section{4 易降解有机质在沉积物颗粒中的分布规律}

巢湖表层沉积物中 TOC 含量与 BPC、CHO、LPD、PRT 含量都呈极显著正相关, BPC 含量也与 CHO、 LPD、PRT 含量呈极显著正相关 (表 2).TOC 含量与粒径小于 $16 \mu \mathrm{m}$ 的表层沉积物呈显著正相关, 与粒径大 于 $16 \mu \mathrm{m}$ 的表层沉积物以及中值粒径呈显著负相关, 表明有机碳主要吸附在 $16 \mu \mathrm{m}$ 以下的沉积物颗粒中; $\mathrm{BPC}$ 含量与粒径 $8 \mu \mathrm{m}$ 以下的表层沉积物呈极显著正相关; PRT 含量与粒径小于 $16 \mu \mathrm{m}$ 的表层沉积物呈显 著正相关; CHO 含量与粒径小于 $8 \mu \mathrm{m}$ 的表层沉积物呈显著正相关; 而 LPD 含量与粒径为 $8 \sim 16 \mu \mathrm{m}$ 的表层 沉积物呈显著正相关, 可能与浮游动物和硅藻的粒径有关.TOC、BPC、PRT、CHO 含量与粒径小于 $8 \mu \mathrm{m}$ 的表 
层沉积物都呈显著正相关, 尤其与粒径为 $4 \sim 8 \mu \mathrm{m}$ 的沉积物相关关系更显著, 表明表层沉积物有机成分主要 集中在粒径 $8 \mu \mathrm{m}$ 以下的颗粒中, 尤以 $4 \sim 8 \mu \mathrm{m}$ 的沉积物颗粒为主. 虽然粒度测定预处理过程加人了过氧化 氢来去除有机质, 但是已有相关研究表明藻类可以产生以及清除过氧化 氢 $^{[69]}$; 另外, 李键等 ${ }^{[70]}$ 和刘娟等 ${ }^{[71]}$ 在对沉积物中硅藻的提纯中都用到了过氧化氢, 因此粒度预处理过程中并未对藻类碎屑产生影响. 有研究表 明蓝藻藻团大部分粒径分布在 $30 \sim 300 \mu \mathrm{m}$ 范围内 ${ }^{[72]}$, 蓝藻个体是大约为 $3 \sim 7 \mu \mathrm{m}$ 的单细胞 ${ }^{[73]}$; 蓝藻死亡 后, 藻团逐渐分裂为个体及死亡碎屑残体 ${ }^{[74]}$. 因此经过预处理测定的粒径为 $4 \sim 8 \mu \mathrm{m}$ 的沉积物颗粒中可能 有一部分是由藻类碎屑组成.

表 2 各指标间的 Pearson 相关系数 $(n=44)$

Tab.2 Pearson correlation coefficients of each index $(n=44)$

\begin{tabular}{|c|c|c|c|c|c|c|c|c|c|c|}
\hline 指标 & TOC & $\mathrm{BPC}$ & $\mathrm{CHO}$ & LPD & PRT & $<4 \mu \mathrm{m}$ & $4 \sim 8 \mu \mathrm{m}$ & $8 \sim 16 \mu \mathrm{m}$ & $16 \sim 63 \mu \mathrm{m}$ & $>63 \mu \mathrm{m} D_{50}{ }^{1)}$ \\
\hline TOC & 1 & & & & & & & & & \\
\hline $\mathrm{BPC}$ & $0.791^{* *}$ & 1 & & & & & & & & \\
\hline $\mathrm{CHO}$ & $0.556^{* *}$ & $0.814^{* * *}$ & 1 & & & & & & & \\
\hline LPD & $0.438^{* *}$ & $0.800^{* * *}$ & $0.492^{* *}$ & 1 & & & & & & \\
\hline PRT & $0.901^{* *}$ & $0.766^{\text {** }}$ & $0.445^{* * *}$ & $0.395^{* *}$ & 1 & & & & & \\
\hline$<4 \mu \mathrm{m}$ & $0.543^{* *}$ & $0.407^{\text {** }}$ & $0.332 *$ & 0.175 & $0.471^{* * *}$ & 1 & & & & \\
\hline $4 \sim 8 \mu \mathrm{m}$ & $0.742^{* * *}$ & $0.493^{* *}$ & $0.303^{*}$ & 0.257 & $0.623^{* * *}$ & $0.790^{* * *}$ & 1 & & & \\
\hline $8 \sim 16 \mu \mathrm{m}$ & $0.335^{*}$ & 0.274 & -0.007 & $0.338^{*}$ & $0.320^{*}$ & 0.028 & $0.401^{\text {*** }}$ & 1 & & \\
\hline $16 \sim 63 \mu \mathrm{m}$ & $-0.684^{* *}$ & $-0.484^{* * *}$ & -0.290 & $-0.309^{*}$ & $-0.561^{* * *}$ & $-0.851^{* * *}$ & $-0.964^{* * *}$ & -0.438 *** & 1 & \\
\hline$>63 \mu \mathrm{m}$ & $-0.363^{*}$ & $-0.310^{*}$ & -0.121 & -0.163 & $-0.461^{\text {*** }}$ & $-0.310^{*}$ & $-0.368 *$ & $-0.646^{* *}$ & $0.352^{*}$ & 1 \\
\hline$D_{50}$ & $-0.659^{* *}$ & $-0.483^{* *}$ & -0.290 & -0.297 & $-0.570^{\text {** }}$ & $-0.909^{* *}$ & $-0.913^{* *}$ & $-0.394^{* *}$ & $0.966^{* *}$ & $0.458^{* *}$ \\
\hline
\end{tabular}

1) $D_{50}$ 表示中值粒径; * 表示显著相关, $P<0.05$; ** 表示极显著相关, $P<0.01$.

\section{3 结论}

在大型浅水富营养化湖泊中, 巢湖全湖样点表层沉积物中 TOC 平均含量达到了 $1.24 \%$, 有机质含量较 高.采用 BPC 指标能够较好地反映巢湖湖底表层沉积物易降解成分的含量, 其占 TOC 的比重介于 $30.99 \%$ $60.48 \%$ 之间, 平均值为 $43.17 \%$, BPC 总体上呈现出西湖区含量高、中湖区含量低, 冬春季节含量高、夏季含 量低的时空分布特征.

有机成分及其中的易降解部分均主要集中于粒径小于 $8 \mu \mathrm{m}$ (尤其是 $4 \sim 8 \mu \mathrm{m}$ ) 的表层沉积物中, 因此在 对造成水体缺氧事件的易降解成分的分析, 或者是在运用工程技术手段处理降解表层沉积物中的过量有机 质时,更应该关注粒径为 $4 \sim 8 \mu \mathrm{m}$ 的沉积物颗粒.

国外已通过对生物易降解成分的分析划分海底表层沉积物的营养等级, 目前未出现关于湖底沉积物营 养等级划分的相关研究. 在掌握巢湖表层沉积物中易降解成分的分布特征的基础上, 后续工作将对湖底的营 养状况进行明确的划分, 这将为巢湖 “湖泛” 预警、湖底过度富营养有机质的强化降解以及湖底越冬蓝藻的 清除提供有力的理论支撑.

致谢: 感谢安徽省巢湖管理局为采样提供方便; 实验分析、文章作图以及初稿修改得到了曹晓祥、徐宪根、尚 丽霞等的帮助, 在此致以诚挚的感谢.

\section{4 参考文献}

[ 1 ] Yin H, Deng J, Shao S et al. Distribution characteristics and toxicity assessment of heavy metals in the sediments of Lake Chaohu, China. Environmental Monitoring and Assessment, 2011, 179(1/2/3/4) : 431-442.

[2] 孙贤斌. 巢湖生态环境污染与防治对策. 国土与自然资源研究, 2001, 3: 50-52.

[ 3 ] Liu E, Shen J, Yang X et al. Spatial distribution and human contamination quantification of trace metals and phosphorus in the sediments of Chaohu Lake, a eutrophic shallow lake, China. Environmental Monitoring and Assessment, 2012, 184 
(4) : 2105-2118.

[ 4 ] 刘 莹. 巢湖蓝藻富营养化监测与预警优化研究 [学位论文]. 合肥: 合肥工业大学, 2012.

[ 5 ] Chase JM. Are there real differences among aquatic and terrestrial food webs? Trends in Ecology and Evolution, 2000,15 (10): 408-412.

[ 6 ] Nowlin WH, Vanni MJ, Yang LH. Comparing resource pulses in aquatic and terrestrial ecosystems. Ecology, 2008,89 (3) : 647-659.

[ 7 ] Shurin JB, Gruner DS, Hillebrand H. All wet or dried up? Real differences between aquatic and terrestrial food webs. Proceedings of the Royal Society B: Biological Sciences, 2006, 273(1582) : 1-9.

[ 8 ] Schroeder F. Water quality in the Elbe estuary : Significance of different processes for the oxygen deficit at Hamburg. Environmental Modeling and Assessment, 1997, 2(1/2): 73-82.

[9]陈荷生. 太湖宜兴近岸水域“湖泛”现象初析. 水利水电科技进展, 2011, 31(4): 33-37.

[10］刘国锋, 何 俊, 范成新等. 藻源性黑水团环境效应: 对水一沉积物界面处 Fe、Mn、S 循环影响. 环境科学, 2010, 31(11): 2652-2660.

[11］王成林, 张 咏, 张宁红等. 太湖藻源性“湖泛”形成机制的气象因素分析. 环境科学, 2011, 32(2) : 401-408.

[12] 申秋实, 周麒麟, 邵世光等. 太湖草源性“湖泛”水域沉积物营养盐释放估算. 湖泊科学, 2014, 26(2) : 177-184. DOI 10. 18307/2014. 0202.

[13] Fabiano M, Danovaro R, Fraschetti S. A three-year time series of elemental and biochemical composition of organic matter in subtidal sandy sediments of the Ligurian Sea(northwestern Mediterranean). Continental Shelf Research, 1995, 15(11/ 12) : 1453-1469.

[14] Viollier E, Rabouille C, Apitz SE et al. Benthic biogeochemistry : state of the art technologies and guidelines for the future of in situ survey. Journal of Experimental Marine Biology and Ecology, 2003, 285/286: 5-31.

[15] Graf G, Schulz R, Peinert R et al. Benthic response to sedimentation events during autumn to spring at a shallow-water station in the Western Kiel Bight. 1. Analysis of the processes on the community level. Marine Biology, 1983, 77 (3): 235-246.

[16] Grant J, Hargrave BT. Benthic metabolism and the quality of sediment organic carbon. Biological Oceanography, 1987, 4 (3) : 243-264.

[17] Dell'anno A, Fabiano M, Mei ML et al. Enzymatically hydrolysed protein and carbohydrate pools in deep-sea sediments: estimates of the potentially bioavailable fraction and methodological considerations. Marine Ecology Progress Series, 2000, 196: $15-23$.

[18] Dell'anno A, Mei ML, Pusceddu A et al. Assessing the trophic state and eutrophication of coastal marine systems: a new approach based on the biochemical composition of sediment organic matter. Marine Pollution Bulletin, 2002, 44(7): 611-622.

[19] Pusceddu A, Dell’anno A, Danovaro R et al. Enzymatically hydrolyzable protein and carbohydrate sedimentary pools as indicators of the trophic state of detritus sink systems: A case study in a Mediterranean coastal lagoon. Estuaries, 2003,26 (3) : 641-650.

[20] 李 强, 霍守亮, 王晓伟等. 巢湖及其入湖河流表层沉积物营养盐和粒度的分布及其关系研究. 环境工程技术学 报, 2013, 3(2): 147-155.

[21] 刘 成, 邵世光, 范成新等. 巢湖重污染汇流湾区沉积物营养盐分布与释放风险. 环境科学研究, 2014, 27(11)： 1258-1264.

[22] 王广召, 方 涛, 唐 巍等. 疏浚对巢湖重污染人湖河流沉积物中污染物赋存及释放的影响. 湖泊科学, 2014,26 (6) : 837-843. DOI 10. 18307/2014. 0604.

[23] 余秀娟, 霍守亮, 备逢宇等. 巢湖表层沉积物中重金属的分布特征及其污染评价. 环境工程学报, 2013, 7(2): 439-450.

[24] 杜臣昌, 刘恩峰, 羊向东等. 巢湖沉积物重金属富集特征与人为污染评价. 湖泊科学, 2012, 24(1): 59-66. DOI 10. $18307 / 2012$. 0108 .

[25] 宋慧婷, 吴振斌, 贺 锋等. 武汉月湖和莲花湖表层沉积物中持久性有机物的污染状况. 长江流域资源与环境, 2008, 17(3) : 431-435.

[26] Joseph MM, Kumar CSR, Kumar TRG et al. Biogeochemistry of surficial sediments in the intertidal systems of a tropical 
environment. Chemistry and Ecology, 2008, 24(4) : 247-258.

[27] Brown MR, Jeffrey SW, Volkman JK et al. Nutritional properties of microalgae for mariculture. Aquaculture, 1997,151 $(1 / 2 / 3 / 4): 315-331$.

[28] Whyte JNC. Biochemical composition and energy content of six species of phytoplankton used in mariculture of bivalves. Aquaculture, 1987, 60(3/4): 231-241.

[29] Brown MR. The amino-acid and sugar composition of 16 species of microalgae used in mariculture. Journal of Experimental Marine Biology and Ecology, 1991, 145(1) : 79-99.

[30] Gatenby CM, Orcutt DM, Kreeger DA et al. Biochemical composition of three algal species proposed as food for captive freshwater mussels. Journal of Applied Phycology, 2003, 15(1): 1-11.

[31] Lopez-Fernandez P, Bianchelli S, Pusceddu A et al. Bioavailable compounds in sinking particulate organic matter, Blanes Canyon, NW Mediterranean Sea: Effects of a large storm and sea surface biological processes. Progress in Oceanography, 2013, 118: 108-121.

[32] Fichez R. Suspended particulate organic matter in a Mediterranean submarine cave. Marine Biology, 1991, 108(1): 167-174.

[33] Fichez R. Composition and fate of organic-matter in submarine cave sediments-implications for the biogeochemical cycle of organic-carbon. Oceanologica Acta, 1991, 14(4) : 369-377.

[34] Danovaro R, Fabiano M, Della Croce N. Labile organic matter and microbial biomasses in deep-sea sediments (Eastern Mediterranean Sea). Deep Sea Research Part I: Oceanographic Research Papers, 1993, 40(5) : 953-965.

[35] Tselepides A, Polychronaki T, Marrale D et al. Organic matter composition of the continental shelf and bathyal sediments of the Cretan Sea(NE Mediterranean). Progress in Oceanography, 2000, 46(2/3/4): 311-344.

[36] Ryba SA, Burgess RM. Effects of sample preparation on the measurement of organic carbon, hydrogen, nitrogen, sulfur, and oxygen concentrations in marine sediments. Chemosphere, 2002, 48(1): 139-147.

[37] Tung JWT, Tanner PA. Instrumental determination of organic carbon in marine sediments. Marine Chemistry, 2003,80 $(2 / 3): 161-170$.

[38] Tanner PA, Leong LS. The effects of different drying methods for marine sediment upon moisture content and metal determination. Marine Pollution Bulletin, 1995, 31(4-12) : 325-329.

[39] 王君波, 鞠建廷, 朱立平. 两种激光粒度仪测量湖泊沉积物粒度结果的对比. 湖泊科学, 2007, 19(5): 509-515. DOI 10. 18307/2007. 0503.

[40] King P, Kennedy H, Newton PP et al. Analysis of total and organic carbon and total nitrogen in settling oceanic particles and a marine sediment : an interlaboratory comparison. Marine Chemistry, 1998, 60(3/4) : 203-216.

[41] Lowry OH, Rosebrough NJ, Farr AL et al. Protein measurement with the Folin phenol reagent. Journal of Biological Chemistry, $1951,193(1): 265-275$.

[42] Hartree EF. Determination of protein: A modification of the lowry method that gives a linear photometric response. Analytical Biochemistry, 1972, 48(2): 422-427.

[43] Mayer L, Schick LL, Setchell FW. Measurement of protein in nearshore marine sediments. Marine Ecology-progress Series, 1986, 30: 159-165.

[44] Gerchakov SM, Hatcher PG. Improved technique for analysis of carbohydrates in sediments. Limnology and Oceanography, 1972, 17(6) : 938-943.

[45] Bligh E, Dyer WJ. A rapid method of total lipid extraction and purification. Canadian Journal of Biochemistry and Physiology, 1959, 37(8): 911-917.

[46] Marsh JB, Weinstein DB. Simple charring method for determination of lipids. Journal of Lipid Research, 1966, 7(4) : 574-576.

[47] Frostegård, Tunlid A, Bååth E. Microbial biomass measured as total lipid phosphate in soils of different organic content. Journal of Microbiological Methods, 1991, 14(3): 151-163.

[48] Fabiano M, Danovaro R. Composition of organic matter in sediments facing a river estuary (Tyrrhenian Sea) : relationships with bacteria and microphytobenthic biomass. Hydrobiologia, 1994, 277(2) : 71-84.

[49] Meyers PA, Ishiwatari R. Lacustrine organic geochemistry - an overview of indicators of organic matter sources and diagenesis in lake sediments. Organic Geochemistry, 1993, 20(7) : 867-900. 
[50］庞晓宇, 吴静汇. 夏季巢湖叶绿素 $\mathrm{a}$ 的时空分布特征研究. 环境科技, 2013, 26(6) : 1-4.

[51] 潘成荣, 汪家权, 郑志侠等. 巢湖沉积物中氮与磷赋存形态研究. 生态与农村环境学报, 2007, 23(1) : 43-47.

[52] 王 娜, 徐德琳, 郭 璇等. 太湖沉积物微生物生物量及其与碳、氮、磷的相关性. 应用生态学报, 2012, 23(7): 1921-1926.

[53] Diaz RJ, Rosenberg R. Spreading dead zones and consequences for marine ecosystems. Science, 2008, 321 ( 5891 ): 926-929.

[54] 李青芹, 霍守亮, 处逢宇等. 我国湖泊沉积物营养盐和粒度分布及其关系研究. 农业环境科学学报, 2010,29 (12) : 2390-2397.

[55] 王小雷, 杨 浩, 顾祝军等. 抚仙湖沉积物中营养盐和粒度垂向分布及相关性研究. 环境工程技术学报, 2014, 4 ( 5) : 353-360.

[56] Harriague AC, Misic C, Petrillo M et al. Stressors affecting the macrohenthic community in Rapallo Harbour ( Ligurian Sea, Italy). Scientia Marina, 2007, 71(4) : 705-714.

[57 ] Dell'anno A, Pusceddu A, Langone L et al. Biochemical composition and early diagenesis of organic matter in coastal sediments of the NW Adriatic Sea influenced by riverine inputs. Chemistry and Ecology, 2008, 24(1) : 75-85.

[58］姜 霞, 王书航, 钟立香等. 巢湖藻类生物量季节性变化特征. 环境科学, 2010, 31(9): 2056-2062.

[59］ 孔繁翔, 高 光. 大型浅水富营养化湖泊中蓝藻水华形成机理的思考. 生态学报, 2005, 25(3): 589-595.

[60] Rabouille S, Salencon MJ. Functional analysis of Microcystis vertical migration: a dynamic model as a prospecting tool. II. Influence of mixing, thermal stratification and colony diameter on biomass production. Aquatic Microbial Ecology, 2005,39 (3) : 281-292.

[61] Gómez-Erache M, Vizziano D, Muniz P et al. The health of the Río de la plata system: Northern Coast, Uruguay. In: Chopin T, Wells PG eds. Opportunity and challenges for protecting, restoring and enhancing coastal habitats in the Bay of Fundy. Proceedings of the Fourth Bay of Fundy Science Workshops, Saint John, New Brunswick. Environment Canada, Atlantic Region. Occasional Report N 17. Environment Canada, Darmouth, Nova Scotia, 2001.

[62] Baldi F, Marchetto D, Pini F et al. Biochemical and microbial features of shallow marine sediments along the Terra Nova Bay (Ross Sea, Antarctica). Continental Shelf Research, 2010, 30(15) : 1614-1625.

[63] 刘菲菲. 巢湖藻源性有机物释放特征及控制 [ 学位论文]. 南京: 中国科学院南京地理与湖泊研究所, 2014.

[64] Pusceddu A, Dell’anno A, Fabiano M et al. Quantity and bioavailability of sediment organic matter as signatures of benthic trophic status. Marine Ecology Progress Series, 2009, 375: 41-52.

[65] Pusceddu A, Gambi C, Zeppilli D et al. Organic matter composition, metazoan meiofauna and nematode biodiversity in Mediterranean deep-sea sediments. Deep Sea Research Part II : Topical Studies in Oceanography, 2009, 56(11/12): 755-762.

[66] Albertelli G, Covazzi-Harriague A, Danovaro R et al. Differential responses of bacteria, meiofauna and macrofauna in a shelf area(Ligurian Sea, NW Mediterranean) : role of food availability. Journal of Sea Research, 1999, 42(1) : 11-26.

[67] Pusceddu A, Fraschetti S, Mirto S et al. Effects of intensive mariculture on sediment biochemistry. Ecological Applications, 2007, 17(5): 1366-1378.

[68] Duros P, Fontanier C, Metzger E et al. Live(stained) benthic foraminifera in the Whittard Canyon, Celtic margin( NE Atlantic). Deep Sea Research Part I : Oceanographic Research Papers, 2011, 58(2) : 128-146.

[69] 郑金秀, 彭 祺, 张甲耀等. 藻类产生及清除过氧化氢的研究. 微生物学杂志, 2006, 26(6) : 80-84.

[70] 李 键, 陈敬安. 湖泊沉积物硅藻提纯方法. 地球与环境, 2007, 35(1):91-96.

[71] 刘 娟, 段昌兵, 唐红渠等. 沉积物硅藻提纯方法的优化. 生态科学, 2013, 32(6) : 763-768.

[72] 范 帆, 李文朝, 柯 凡. 巢湖市水源地铜绿微囊藻 (Microcystis aeruginosa) 藻团粒径时空分布规律. 湖泊科学, 2013, 25(2) : 213-220. DOI 10. 18307/2013. 0206.

[73] 黄 维. 一种新型蓝藻清除机械的除藻机理及除藻试验研究 [学位论文]. 长沙: 湖南农业大学, 2009.

[74] 叶 云, 刘文汇, 腾格尔等. 巢湖蓝藻腐殖化过程中形态与成份变化研究. 微体古生物学报, 2012, 29(2): 152-160. 